\title{
Analysis on Operational Cost of Modern Tram
}

\author{
Zhao Xinmiao $^{1^{*}}$, Sun Quanxin ${ }^{1}$, Liu Lu ${ }^{1}$, Ding Yong ${ }^{1}$, Shi Ruijia ${ }^{1}$
}

(1. MOE Key Laboratory for Urban Transportation Complex Systems Theory and Technology, Beijing Jiaotong University, Beijing 100044)

*zhaoxm@bjtu.edu.cn

Keywords: urban rail transit; modern tram; operational cost; sensitivity analysis

Abstract: Operational cost of modern tram consists of the wage, maintenance cost, power consumption cost, management cost and other cost. This paper subdivided the influential factors of traction energy consumption and maintenance cost according to fixed cost and variable cost, and a method is proposed to analyze operational cost. Taking a tramline for example, the sensitivity of passenger volume and the frequency are analyzed. Results show that a double increase of ridership rarely raises annual operational cost by $5.1 \%$ while sharply reduces operational cost per capita by 47.5\%; an additional $100 \%$ increase of the frequency raises the operational cost by $22.7 \%$ while reduces operational cost per capita by $38.6 \%$. Consequently, this paper recommends increasing the frequency to enhance competitiveness of modern tram in case of large passenger flow volume, and vice versa.

\section{Introduction}

Modern trams are powered by the contact net and belong to the rail transit with small light vehicle marshalling running on the track. The tracks cross the road in a planar form and some cities regard tram as one type of light rail. With the development of major cities, public transport-oriented urban transport system is applied to relieve traffic congestion, environmental pollution and other problems. Due to the characteristics of proper capacity, economical investment and friendly environmental, modern trams have got much attention from many cities. Nowadays modern tram has just evolved in China. Modern trams have been under operation in Shanghai, Tianjin and Dalian. The construction projects have started in Beijing, Shenyang and Wuhan. Since the lack of operation practice of modern tram, the study of operational cost estimation of modern tram is very meaningful and will give some advices for the enterprises which focus on the economic benefits.

\section{Components Analysis of Operational Cost}

As we know, there are many mature researches about operational cost of urban rail transit, including the analysis of transportation cost structure[1-3]. However, the study of modern tram only focused on cost investment[4] and technically economic applicability[5]. In foreign countries, the tram operation and bus operation usually belong to the same company and this leads to the lack of independent cost estimation of modern tram.

The operational cost of modern tram consists of five aspects, covering the wage, maintenance

\footnotetext{
${ }^{1}$ National Key Basic Research Development Program (2012CB725406); National Natural Science Foundation of China (71131001) and National Natural Science Foundation of China (71571016).
} 
cost, power consumption cost, management cost and other cost[6]. According to the effect of operation, the annual cost can be divided into two parts, including variable cost and fixed cost. The former changes with the operational work, such as passenger number and travel distance[7]. The latter can be considered as a fixed cost in a proper range. This paper ignores the cost of new re-purchased vehicles and updating railway lines. Based on the classification principles, the maintenance cost is divided into EMU maintenance cost and fixed equipment maintenance cost. The power consumption cost is subdivided into traction power consumption cost and lighting consumption cost of stations.

\section{Model Construction}

The estimation model of modern tram operational cost is

$$
C O=F C+V C=C_{t}+C_{v m}+C_{w}+C_{f m}+C_{p l}+C_{m}+C_{e}
$$

Where $C O$ denotes the operational cost; $F C$ denotes the fixed cost; $V C$ denotes the variable cost; $C_{t}$ denotes the traction power consumption cost; $C_{v m}$ denotes the EMU maintenance cost; $C_{w}$ denotes the wage; $C_{f m}$ denotes the fixed equipment maintenance cost; $C_{p l}$ denotes the lighting consumption cost of stations; $C_{e}$ denotes the other expenses.

\section{Variable Cost \\ Traction Power Consumption Cost}

The traction power consumption cost concerns with the running distance of vehicles and is estimated by the power price, the vehicle running distance and the power consumption per kilometer[8]. Generally, the passenger number increases with the operation time. When the passenger number becomes large, the passenger weight cannot be ignored. In the model, the traction weight consists of passenger weight and vehicle weight. The traction force is affected by the traction power and technical speed[9]. The influence factors of traction power consumption cost are practical power, frequency, and running distance. The practical power has positive correlation with fixed power, technical speed and passenger weight. So the traction power consumption cost can be evaluated by

$$
C_{t}=C_{p t}+C_{v t}=P_{e} N_{v} V_{v} v c\left(m_{v} \bar{S}+\bar{P} m_{p} \bar{S}_{p}\right)
$$

Where $C_{t}$ denotes the traction power consumption cost; $C_{p t}$ denotes the cost affected by passenger weight; $C_{v t}$ denotes the cost affected by vehicle weight; $P_{e}$ denotes the power price; $N_{v}$ denotes the number of vehicles; $V_{v}$ denotes the fixed power; $v$ denotes the technical speed; $c$ denoted the quantitative constant; $m_{v}$ denotes the vehicle weight without passengers; $\bar{S}$ denotes the frequency; $\bar{P}$ denotes the average passenger numbers on the vehicle; $m_{p}$ denotes the average weight per capita; $\bar{S}_{p}$ denotes the average distance per capita.

\section{EMU Maintenance Cost}

The EMU maintenance cost can be calculated by

$$
C_{v m}=\overline{C_{v m}} N_{v} \bar{S}
$$

Where $C_{v m}$ denotes the maintenance cost per kilometer per vehicle; $N_{v}$ denotes the annual 
operation vehicles per year.

\section{Fixed Cost}

The wage depends on the number of equipped managers serving for the company operation and the industry average wage level. The maintenance cost is used to purchase the infrastructure and equipment system, including the daily maintenance cost[10]. The light consumption cost of stations is used to ensure the operation of air conditioning, elevators, ventilation and other power equipments. The management cost covers the expense of office facilities, travel on business and public propaganda. The cost which belong to none of the terms list in the paper can be calculated as the other expense and is given a number of ten percent of the annual cost.

$$
F C=N_{e} \overline{C_{w}}+C_{f}+C_{c m}+C_{p l}+P \overline{C_{m}}+(1+10 \%) \cdot\left(C_{t}+C_{v m}+C_{w}+C_{f m}+C_{p l}+C_{m}\right)
$$

Where $N_{e}$ denotes the number of equipped operation managers; $\overline{C_{w}}$ denotes the industry average wage level; $C_{f}$ denotes the imported material cost of accessories; $C_{c m}$ denotes the daily maintenance cost; $C_{p l}$ denotes the light consumption cost of stations; $P$ denotes the passenger flow volume per year; $\overline{C_{m}}$ denotes the management cost per capita.

\section{Case Study}

This paper takes a real tram-line as an example, which formally began to operate in 2010 . This line shares the road with other vehicles, and the number of the stations is 15 , which are located in the city's Science and Technology Park. The starting point of the line connects with a subway station, and the number of drivers and conductors is 140. The vehicles are Raul's LOHR Translohr STE3 from French with three vehicle marshalling. The annual number of vehicles is nine, including seven in operation, one for preparation, and another for maintenance. The related parameters are shown in Table 1.

Table1 Parameters of the line

\begin{tabular}{|c|c|c|c|c|}
\hline parameter & $\begin{array}{l}\text { technical } \\
\text { speed } v\end{array}$ & $\begin{array}{c}\text { annual } \\
\text { operational } \\
\text { kilometers } S\end{array}$ & $\begin{array}{l}\text { average annual } \\
\text { wage of the industry }\end{array}$ & $\begin{array}{c}\text { designed daily } \\
\text { passenger flow } \\
\text { volume } \overline{p_{d}}\end{array}$ \\
\hline value & $13.8 \mathrm{~km} / \mathrm{h}$ & $480,000 \mathrm{~km}$ & 78,797.34yuan & 20,000 \\
\hline parameter & $\begin{array}{l}\text { imported } \\
\text { material cost of } \\
\text { accessories } C_{f}\end{array}$ & $\begin{array}{c}\text { maintenance cost } \\
\text { of contact net } \\
\text { and daily } \\
\text { maintenance cost } \\
C_{c m}\end{array}$ & $\begin{array}{c}\text { power consumption } \\
\text { per kilometer per } \\
\text { vehicle }\end{array}$ & $\begin{array}{l}\text { the price of } \\
\text { electricity }\end{array}$ \\
\hline value & $\begin{array}{c}5 \text { million yuan } \\
\text { per year }\end{array}$ & $\begin{array}{l}3.4 \text { million yuan } \\
\text { per year }\end{array}$ & $6 \mathrm{kw}$ & 0.8 yuan $/ \mathrm{kw}$ \\
\hline parameter & $\begin{array}{l}\text { cost per } \\
\text { kilometer }\end{array}$ & $\begin{array}{l}\text { the weight of } \\
\text { vehicles } m_{v}\end{array}$ & $\begin{array}{l}\text { average weight of } \\
\text { passegers } m_{p}\end{array}$ & \\
\hline value & 3.8yuan & $23,600 \mathrm{~kg}$ & $65 \mathrm{~kg}$ & \\
\hline
\end{tabular}

The line operation time lasts for 15 hours per day with an average headway of 15 minutes. The daily passenger flow volume is 7000 . Considering most passengers ride from start to end, the average distance is estimated by ten kilometers. The light consumption cost of stations is close to 
the traction power consumption cost[8], the management cost can refer to the management fee of other city. Based on the proposed operating cost estimation models, we have

$$
\begin{aligned}
C O= & (1+10 \%)\left(C_{t}+C_{v m}+C_{w}+C_{f m}+C_{p l}+C_{m}\right) \\
C O= & (1+10 \%)(267.8+182.4+140 \times 78797.34 / 10000+500+340+267.84 \\
& +4052.5 \times 255.5 / 10000)) \times 10000 \text { yuan } \\
C O= & 30.4 \text { million yuan }
\end{aligned}
$$

In conclusion, the annual operation cost is 30.4 million yuan, and the operation cost per capita is 11.9 yuan。

\section{Sensitivity}

The load factor is less than 50\% currently, and passenger demand has more room for growth. When passenger flow volume grows, the operator need to increase the frequency to increase the capacity, so it's necessary to analysis the sensitivity on passenger flow volume and the frequency to study the effect of individual factor and both factors on annual operation cost and operating cost per capita.

\section{Sensitivity of passenger flow volume}

The factors related to passenger flow volume $P$ are $C_{p t}, C_{m}$ in Formula 1, namely traction energy cost caused by passengers' weight and management cost. When passenger flow volume increases by $20 \%, 40 \%, 60 \%, 80 \%$ and $100 \%$, the changes of annual operational cost and operational cost per capita are shown in Figure1.

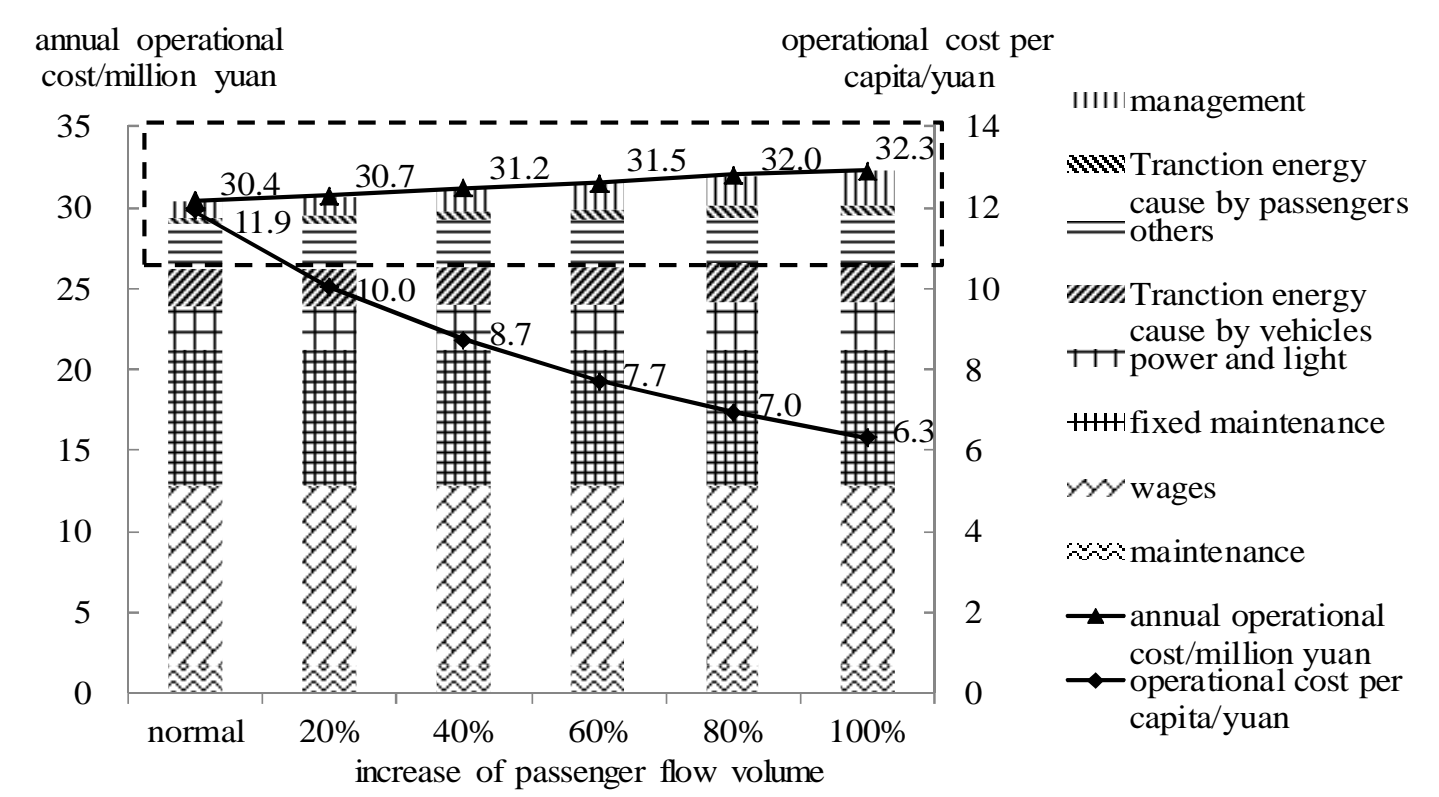

Fig.1 Sensitivity of Passenger flow volume

Figure 1 shows that when passenger flow volume increases by $100 \%$, both traction energy consumption caused by passengers and management cost increase proportionally, and annual operational cost increases from 30.4 million yuan to 32.0 million yuan with a small degree of 5.1\%, while operational cost per capita decreases from 11.9 yuan to 6.3 yuan with a significant degree of $47.5 \%$. Therefore most of the cost is invested at the beginning of operation, and passenger flow 
volume has a small marginal utility on annual operational cost, so it can reach to a state of balance even profitable when passenger flow volume increases.

\section{Sensitivity of passenger flow volume and frequency}

When passenger flow volume increases, more services are needed, and we can improve the utilization of the vehicle by adopting suitable road power or intersection signal priority to make it.

The factors related to passenger flow volume $P$ and frequency $N_{v}$ are $C_{p t}, C_{v t}, C_{v m} 、 C_{m}$ in Formula 1. When $P$ and $N_{v}$ increases by $20 \%, 40 \%, 60 \%, 80 \%$ and $100 \%$, the change of annual operational cost and operational cost per capita are shown in Figure 2.

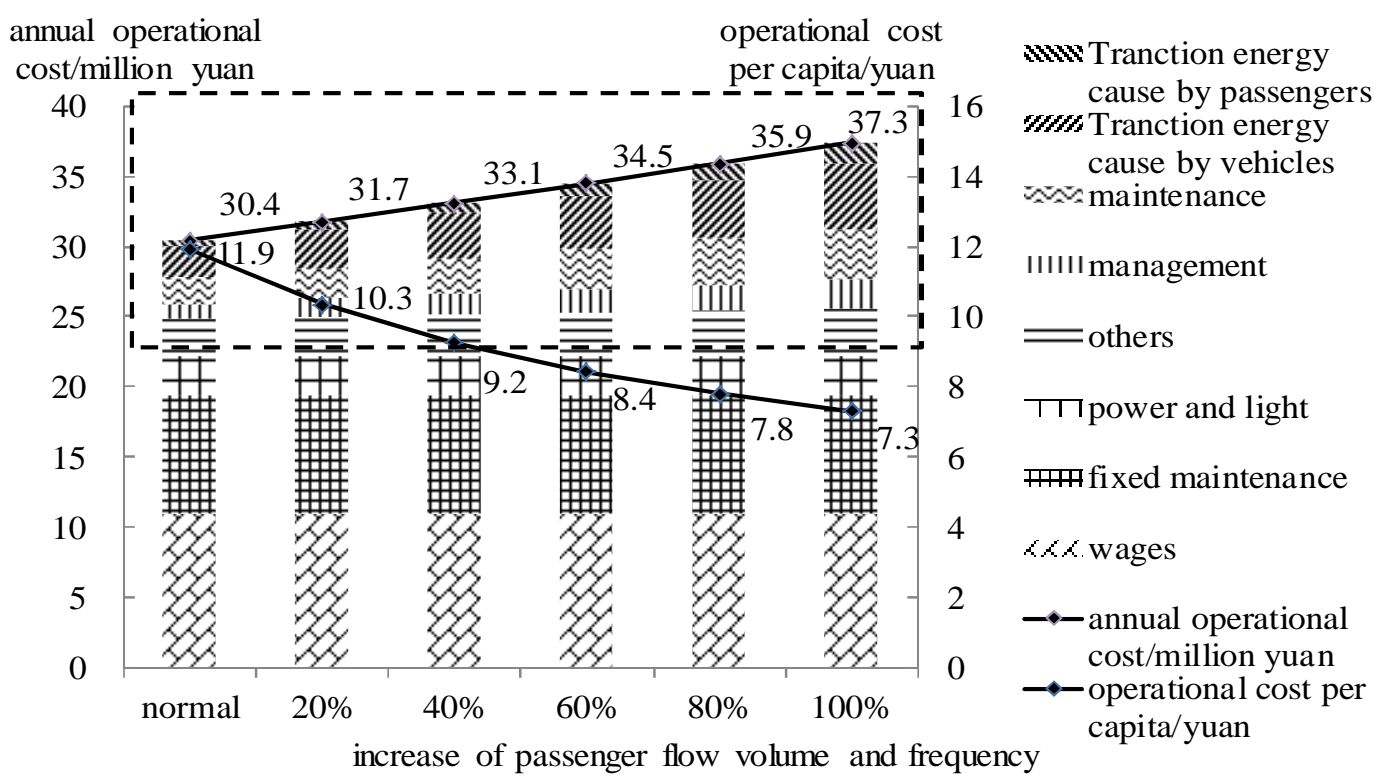

Fig.2 Sensitivity of passenger flow volume and frequency

Figure 2 shows that when $P$ and $N_{v}$ increase by $100 \%$ annual operational cost increases from 30.4 million yuan to 37.3 million yuan with a degree of $22.7 \%$, while operational cost per capita decreases from 11.9 yuan to 7.3 yuan with a degree of $38.6 \%$. In the operational cost, $C_{p t}$ increases sharply and $C_{v t}, C_{v m}$ and $C_{m}$ increase proportionally. Therefore when the frequency is needed to increase to suit to the growth of passenger flow volume, operational cost per capita can be decreased to make the tram more competitive and more attractive; when the passenger volume is small, it's suggested to decrease the frequency to decrease annual operational cost.

\section{Conclusion}

This paper analyzes the components of operational cost of modern tram, and a real tramline is used to verify the method. The effect of passenger flow volume and frequency on annual operational cost and operational cost per capita are analyzed, obtaining the following conclusions:

When passenger flow volume increases, traction energy cost caused by the weight of passengers and management cost increase proportionally, leading to a slow increase of annual operational cost and a sharp decrease of operational cost per capita; when both passenger flow volume and the frequency increase, traction energy cost caused by the weight of passengers 
increases quickly, traction energy cost caused by the weight of vehicles, maintenance cost and management cost increase proportionally, so annual operational cost increases slowly while operational cost per capita decreases quickly. Considering the load factor is less than $50 \%$, this paper suggests decreasing the frequency to save operational cost when passenger flow volume is small, and increasing the frequency to make the tramline more attractive when passenger flow volume increases.

This study neglects the external cost of tram, and the model of operational cost can be more accurate with more real lines, which will be the focus of future research.

\section{Acknowledgements}

This research was supported by National Key Basic Research Development Program (2012CB725406); National Natural Science Foundation of China (71131001) and National Natural Science Foundation of China (71571016).

\section{References}

[1] Mao Baohua. Operations and Management for Urban Rail Transit[M]. China Commutations Press, 2006: 289-291.

[2] Li Wenxing, Yin Shuai. Analysis on Cost of Urban Rail Transit[J]. Journal of Transportation Systems Engineering and Information Technology, 2012, 12(2): 9-14.

[3] Chen Feng, Wang Zijia, Li Zhiqiang. Analysis on Construction Cost of Urban Rail Transit[J]. Railway Transport and Economy, 2008,(9): 53-55.

[4] Qu Yuan, Liu Shiyu. Investment Estimation of Tram and Analysis of National Economic Evaluation[J]. China Municipal Engineering, 2012 (5):84-85.

[5] Zhang Jin, Liang Qinghuai, Sun Fulian, et al. Study on the Applicability of Modern Trams[J]. Urban Rapid Rail Transit, 2013, 26(5).

[6] Li Xinxin. Study on Subsidy Mechanism for Modern Tram Operation[D]. Beijing: Beijing Jiaotong University, 2013.

[7] Song Yujia. Analysis on the Operation Cost and Maintenance Cost of High-speed Railway[J]. Transpo World, 2013 (8): 222-223.

[8] LiuPeng, Tian Qiong. Analysis of Traction Energy Consumption of Urban Rail Transit[J]. Shandong Science, 2012,6(3):7-11.

[9] Wei Chao. The Applicability of Modern Trams[D]. Shanghai: Tongji University, 2008.

[10] Yu Fuli, Jia Junfang, Li Zhiqiang. Study on the Control of urban rail transit's operating costs[J]. Modern Urban Transit, 2009 (2): 53-54. 